Original Research

\title{
Evaluation of Slaughter Stress Responses in the Dromedary Camel
}

\section{Lemrhamed Abdelilah $^{1 *}$, Tabite Rabab ${ }^{1}$, El Abbadi Najia ${ }^{2}$, El Khasmi Mohammed ${ }^{1}$ and Faye Bernard $^{3}$}

${ }^{1}$ Laboratory of Physiopathology and Molecular Genetics, Faculty of Sciences Ben M'Sik, University Hassan II of Casablanca, PB. 7955 Sidi Othmane, Casablanca, MOROCCO

${ }^{2}$ Unit of Radio-Immuno-Analysis/Division of Life Sciences, CNESTEN, PB. 1382 RP 10001, Rabat, MOROCCO

${ }^{3}$ FAO/CIRAD-ES, Campus International de Baillarguet, TA C/dir B 34398 Montpellier, FRANCE

*Corresponding author: lemrhamed-abdelilah@hotmail.fr

Rec. Date:

Accept Date:

DOI
May 27, 2019 13:24

Jul 19, 2019 16:47

$\underline{10.5455 / \mathrm{ij} l \mathrm{r} .20190527012442}$

\begin{abstract}
Slaughter stress responses were evaluated in the dromedary camel by analyzing hematocrit (Hct), neutrophil/lymphocyte ratio (NLR), hemolysis (H\%), catalase activity (CATa) and plasma levels of cortisol $(C O R)$, triiodothyronine $\left(T_{3}\right)$, thyroxine $\left(T_{4}\right)$, glucose and malondialdehyde (MDA). Blood was collected during three different steps: at the arrival of the animals at the slaughterhouse just after unloading (step 1), at the end of a rest period of 16 to 20 hours (step 2) and finally during bleeding (step 3) after exposure to traditional slaughter stress. NLR, H\%, MDA, glucose, COR, T3 and T4 measured at step 2 were significantly $(P<0.05)$ lower compared to those observed at step 1 or step 3 . On the contrary, CATa measured at step 2 were significantly $(P<0.05)$ higher than that analyzed at steps 1 and 3. In the camel, the slaughter procedure used here was much more stressful and was able to alter the physiology of the animal.
\end{abstract}

Key words: Catalase Activity, Dromedary, Glucose, Hormones, Haemolysis, Malondialdehyde, Neutrophil/Lymphocyte Ratio, Slaughter Stress

How to cite: Lemrhamed, A., Tabite, R., Abbadi, N., El Khasmi, M., \& Faye, B. (2019). Evaluation of Slaughter Stress Responses in the Dromedary Camel. International Journal of Livestock Research, 9(8), 78-90. doi: 10.5455/ijlr.20190527012442

\section{Introduction}

In Morocco, the camel population estimated at 180,000 plays an important socio-economic role and provides milk and meat for human population in the South regions. In 2017, camel milk and meat production reached 13,975 t and $3600 \mathrm{t}$, respectively (Ministry of Agriculture, 2018). In all abattoirs of these regions, camels are slaughtered according to the proper Islamic killing procedures (halal slaughter) to fulfill local meat consumers' requirements and several preslaughter stress and oxidant stress responses 
were induced by transport (El Khasmi et al., 2013; El Khasmi et al., 2015), loading density and waiting duration (Lemrhamed et al., 2018a; Lemrhamed et al., 2018b). There are many indicators that are considered important and reliable for assessing stress using physiological (heart and respiratory rates, rectal temperature), hematological (hemolysis, neutrophile/lymphocyte ratio), biochemical and hormonal analysis (enzymes, cortisol, thyroid hormones, glycolytic potential, proteins, oxidative stress, lipid peroxidation, and tissue damage) in domestic animals (Grandin, 1997; Broom, 2014) and the camel in particular (El Khasmi et al., 2013; El Khasmi et al., 2015; Lemrhamed et al., 2018a; Lemrhamed et al., 2018b). In fact, preslaughter stress activates the animals' hypothalamic-pituitary-adrenal axis, resulting in release of various stress hormones such as catecholamines and cortisol, glycogen depletion and elevated muscle ultimate $\mathrm{pH}$ (Njisane and Muchenje, 2017). At the abattoir, the animal perception and stress responses depend on several factors, such as, its background, previous experience, many abattoir workers (Terlouw et al., 1998; Terlouw et al., 2011; Terlouw, 2005), other animals from different farms and of other species (Vimiso et al., 2012) and loud noise at the abattoir (Francesca Iulietto et al., 2018).

The reactivity to human and environmental factors involved in slaughter operations increase blood levels of glucose and cortisol, muscle activity and glycogen and fat mobilization (Kannan et al., 2000; Alcalde et $a l ., 2011$ ) and induce neutrophilia and lymphopenia (Ali et al., 2006; Minka et al., 2009; Miranda de la Lama et al., 2010) in animals owing to stress. Thus, the camel meat consumers and an efficient marketing system of the meat industry need more information on slaughtering practices and its' impact on the meat composition. However, even if animal welfare and its impact on product quality are highly considered in developed countries (Ndou et al., 2011), in the developing ones this phenomenon have received little attention from the scientific researchers (Vimiso et al., 2012). Therefore, this study was conducted to evaluate stress responses induced by the slaughter practice used in one of the abattoirs in Morocco in the camel, by analyzing several indicators such as: hematocrit (Hct), neutrophil/lymphocyte ratio (NLR), hemolysis (H\%), catalase activity (CATa) and plasma levels of cortisol (COR), triiodothyronine $\left(\mathrm{T}_{3}\right)$, thyroxine $\left(\mathrm{T}_{4}\right)$, glucose and malondialdehyde (MDA).

\section{Materials and Methods}

\section{Animal Management and Slaughter Procedure}

The study was conducted at the municipal slaughterhouse of Casablanca in Morocco (North of Africa, latitude $33^{\circ} 34^{\prime} 42.44^{\prime \prime} \mathrm{N}$, longitude $7^{\circ} 36^{\prime} 23.89^{\prime \prime} \mathrm{O}$ ). The abattoir is located $2 \mathrm{~km}$ away from the faculty of sciences Ben M'Sik, and the temperatures during the study ranged from $16^{\circ} \mathrm{C}$ to $21^{\circ} \mathrm{C}$. A total of eight adult male camels (Camelus dromedarius) aged from 4 to 7 years old were used in the study. These animals lived in similar conditions and were fed a concentrate of barley and dry hay straw. After a transport time of about $90 \mathrm{~min}$, in a squatting position holding the forelegs tight by a rope at the knees, the animals arrived at the 
abattoir. They were in good clinical health and were deprived of food one night before, and during transport and lairage. The animals were carefully unloaded on arrival to avoid stress and were quietly transferred to the open-air storage facilities inside the slaughterhouse and were kept in waiting for a period of about $20 \mathrm{~h}$, without feeding but with access to water. Following the rest period, the animals were guided inside the slaughter room at 7:00 am, to be slaughtered according to the halal procedure without any prior stunning. They were placed in a squatting position with the forelegs tied with a rope at the knees. The head was fixed in a caudal position (ie turned towards the tail) and then a quick cut with a sharp knife between the base of the neck and the thorax, quickly bleed the animal by section of the vein's jugular, carotid arteries, esophagus and trachea, without severing the spinal cord. Stress responses were evaluated at the end of the transport just after unloading (step 1), after a rest period of 20h (step 2) and during bleeding after exposure to slaughter stress (step 3).

\section{Blood Samples}

The first blood sample was collected at the end of transport immediately after unloading (step 1), the second sample was collected at the end of the rest period (step 2), while the third blood sample was collected immediately at slaughter (step 3) into 2 Vacutainer test tubes, one containing ethylene diamine tetra acetic dipotassium (EDTA-K2) and the other heparin. EDTA blood was used to measure Hct, NLR and H\%, while heparin blood was used to determine plasma levels of all biochemical parameters. The first and second blood samples were taken by puncture of the left jugular vein with minimum disturbance to avoid excessive stress, both at 11:00 a.m. and 06:45 a.m. respectively. However, the third blood sample was collected during the exsanguination which was carried out 15-30 min after the second sampling. Tubes were kept in ice until plasma was separated within $15 \mathrm{mn}$ of collection by centrifugation at $4^{\circ} \mathrm{C}$ for $10 \mathrm{~min}$ at $3000 \mathrm{rpm}$ placed in $1.5 \mathrm{ml}$ Eppendorf tubes and stored at $-80^{\circ} \mathrm{C}$ until analysis.

\section{Measure of Hematocrit and Neutrophil/Lymphocyte Ratio}

Hct was determined on whole blood with capillary tubes and centrifuged (hettich Haematokrit D-7200) using a micro-hematocrit reading device. To determine the differential distribution of leukocytes (\%), blood smears were stained with May-Grunwald-Giemsa. The percentage of neutrophils, eosinophils, basophils, lymphocytes and monocytes was analyzed, and the NLR were determined as an indicator for assessing stress. In domestic animals (Ali et al., 2006; Minka et al., 2009; Miranda de la Lama et al., 2010) and the dromedary camel (Bargaâ et al., 2016; Lemrhamed et al., 2018), stress induced an increase of NLR.

\section{Hemolysis Test}

The H\% profile was analyzed using the method of O'Dell et al. (1987) with slight modifications. One hundred $\mu \mathrm{l}$ of blood was added to tubes containing $5 \mathrm{ml}$ of various concentrations of buffered saline (BSS, 
$\mathrm{pH}$ 7.4) ranging from $0.1 \%$ to $0.9 \%$. After gentle mixing and incubation at $37{ }^{\circ} \mathrm{C}$ for 30 minutes, the tubes were centrifuged at $1270 \mathrm{xg}$ for $10 \mathrm{~min}$. The supernatant was then transferred to a glass cuvette and the absorbance measured at $540 \mathrm{~nm}$ using a spectrophotometer. The $\mathrm{H} \%$ in each tube was expressed as a percentage, taking as $100 \%$ the maximum value of the absorbance of the distilled water and the red blood cells. BSS (0.9\%) was considered a control sample. The percentage of hemolysis was calculated as follows (Fraukner and King, 1970)-

$$
\mathrm{H}(\%)=[\text { Optical Density }(\mathrm{NaCl}+\text { Blood }) / \text { Optical Density }(\text { Distilled Water + Blood })] \text { x100 }
$$

From the curve obtained by plotting the percentage of hemolysis $(\mathrm{H} \%)$ with respect to saline concentrations, hemolysis 50 (H50) was determined as the concentration of the saline solution (mOsm/L) which hemolyzed $50 \%$ of the red blood cells.

\section{Analysis of Biochemical Parameters}

Plasma levels of glucose were measured using a spectrophotometric procedure from commercially available kits. Those of MDA and plasma CATa were measured by a colorimetric method based on described method of (Satho, 1978; Aebi, 1974) respectively. Briefly, plasma samples were homogenized with cold and were mixed with trichloroacetic acid (TBA) (20\%) and the precipitate was dispersed in $\mathrm{H}_{2} \mathrm{SO}_{4}(0.05 \mathrm{M})$. TBA $(0.2 \%$ in sodium sulfate $2 \mathrm{M})$ was added and heated for $30 \mathrm{~min}$ in boiling water bath. After extraction by $\mathrm{n}$ butanol optical density was measured at $532 \mathrm{~nm}$. Concerning the CATa, the disappearance of hydrogen peroxide $\left(\mathrm{H}_{2} \mathrm{O}_{2}\right)$ was monitored spectrophotometrically at $240 \mathrm{~nm}$ for $5 \mathrm{~min}$, and a molar extinction coefficient of $0.041 / \mathrm{mM} / \mathrm{cm}$ was used. The CATa was defined as the $\mu$ mol decreased $\mathrm{H}_{2} \mathrm{O}_{2} / \mathrm{min} / \mathrm{mg}$ protein. Plasma levels of COR, $\mathrm{T}_{3}$ and $\mathrm{T}_{4}$ were analyzed by radioimmunoassay (RIA) at the National Center for Energy, Science and Nuclear Techniques in Maâmoura, Morocco, using commercially available coated RIA tubes.

Hormones were quantified according to the manufacturer's instructions. These kits have proven effective in previous camel experiments (El Khasmi et al., 2013; El Khasmi et al., 2015) and were purchased from DIAsource (Immunoassays S.A., Nivelles, Belgium). Slopes of rights corresponding to the human standard or camel plasma are not significantly different (Fig. 1). The COR, $\mathrm{T}_{3}$ and $\mathrm{T}_{4}$ assays had a sensitivity of 0.9 $\mathrm{ng} / \mathrm{mL}, 0.1 \mathrm{nM}$ and $5 \mathrm{nM}$ respectively, with intra-assay coefficients of variations of $6.36 \%, 5.15 \%$ and $4.4 \%$ respectively, and inter-assay coefficients of variation of $11.76 \%, 3.35 \%$ and $6.5 \%$ respectively. 

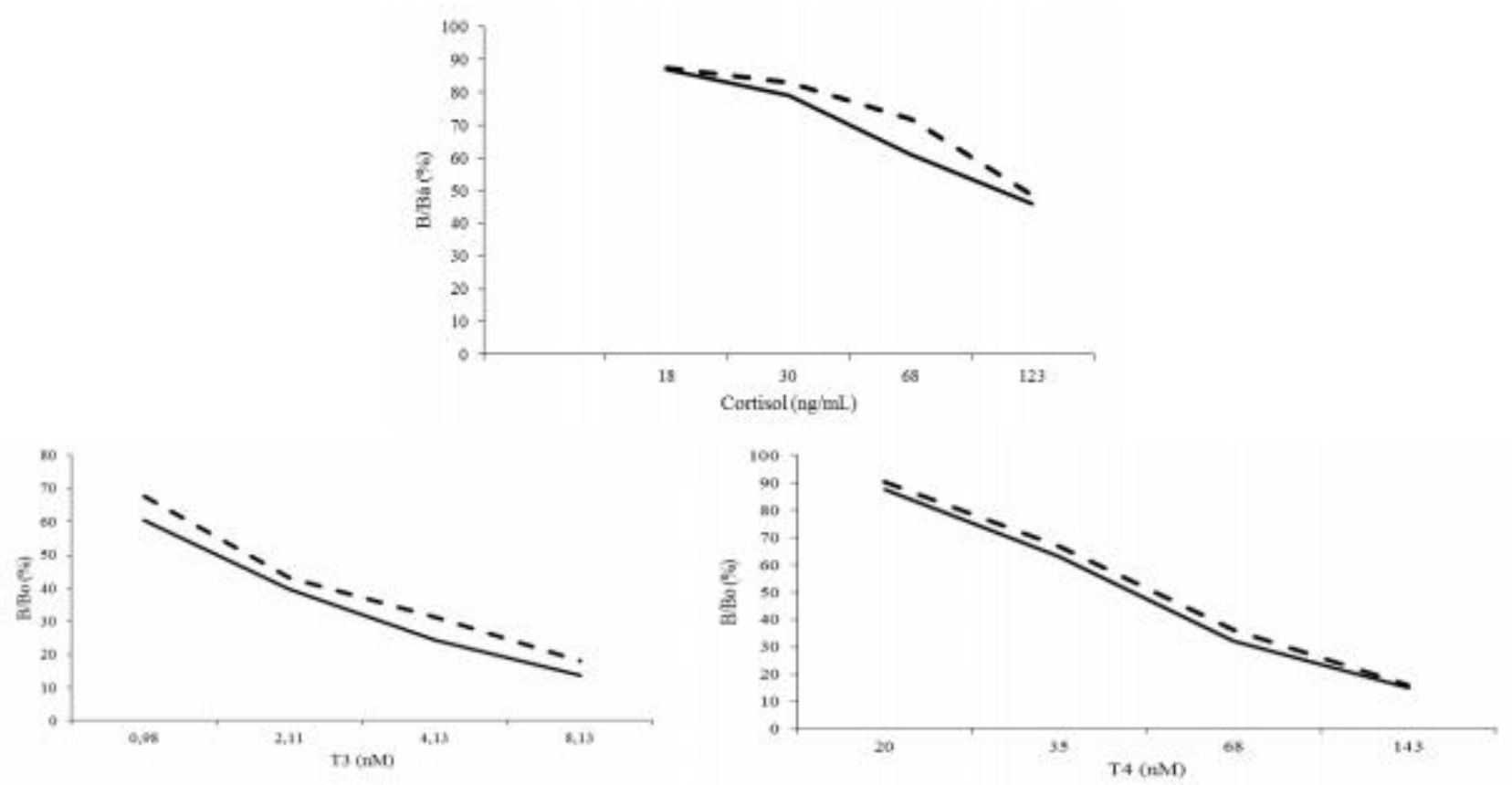

Fig. 1: Comparison of the standard human curve of each hormone (dotted line) with that obtained by dilution of a dromedary plasma (solid line)

\section{Statistical Analysis}

The data were expressed as mean $(\mathrm{M}) \pm$ standard error $(\mathrm{ES})$ and were analyzed by the Freidman test for comparison between the values determined in different groups and at different stages. $\mathrm{P}<0.05$ was seen as statistically significant.

\section{Results}

In this work, the impact of stress induced by the halal slaughter procedure was evaluated by analyzing physiological, hematological, biochemical and endocrine parameters in the dromedary camel. NLR and $\mathrm{H} 50$ values $(\mathrm{mOsm} / \mathrm{L})$ measured after transport and unloading of the animals (step 1) (respectively $1.41 \pm 0.083$ and $121.67 \pm 5.48)$ showed a significant decrease $(\mathrm{P}<0.05)$ after a rest of 20h (step 2) (respectively $0.83 \pm 0.087$ and $104.66 \pm 3.09$ ), then these values increased significantly after the stress of the

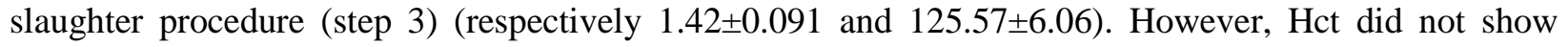
significant variation for the three steps (respectively $34.06 \pm 1.32 ; 32.79 \pm 1.66 ; 34.83 \pm 1.46$ ) (Fig. 2). 


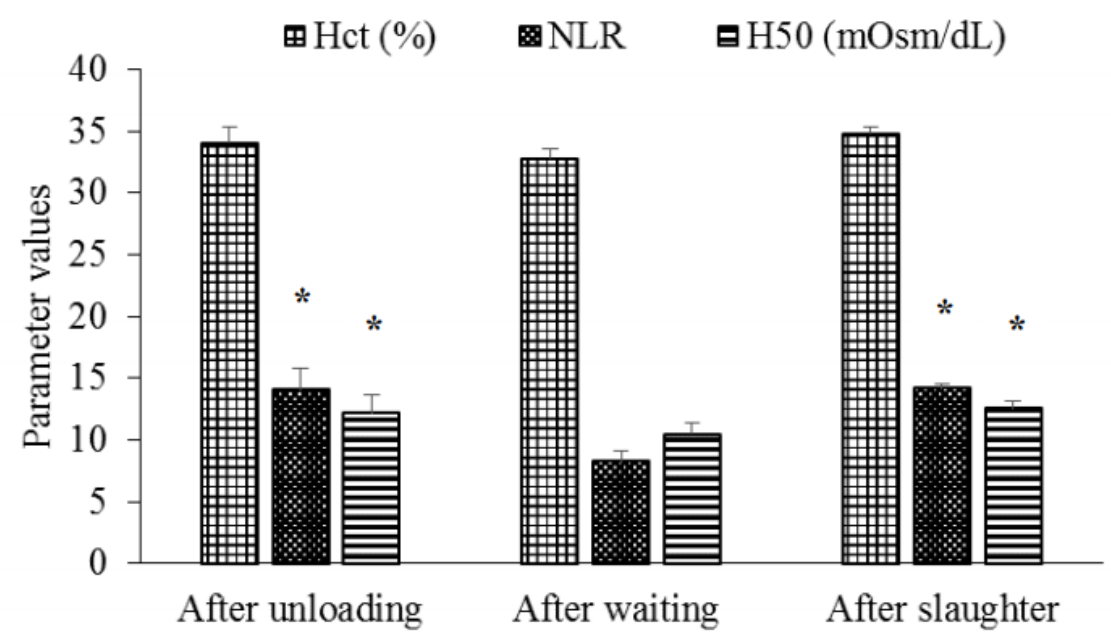

Fig. 2: Hematocrit (Hct), Neutrophile/Lymphocyte Ratio (NLR) and concentration of hypotonic salt solution inducing hemolysis of $50 \%$ of erythrocytes (H50), at 3 successive steps: after road transport (90 $\mathrm{mn}$ ) and unloading (step 1), after a rest period of 20h (step 2) and during bleeding after exposure to halal rite stress without stunning (step 3$)$ in dromedary camels. ( $\mathrm{M} \pm \mathrm{SEM}$, ${ }^{*} \mathrm{P}<0.05$ comparison with step 2)

Results showed that circulating levels of glucose $(\mathrm{mM})$, cortisol $(\mu \mathrm{g} / \mathrm{dL}), \mathrm{T}_{3}(\mathrm{nM})$ and $\mathrm{T}_{4}(\mathrm{nmoles} / \mathrm{dL})$ analyzed after transport and unloading of camels (respectively $7.27 \pm 0.17 ; 6.295 \pm 1.767 ; 4.35 \pm 1.57$ and $21.649 \pm 3.969)$ decreased significantly $(\mathrm{P}<0.05)$ after waiting period (respectively $6.52 \pm 0.33 ; 2.723 \pm 0.757$; $1.69 \pm 0.78$ and $8.076 \pm 1.654$ ), then these values increased significantly after exposure to the slaughter procedure (respectively $7.17 \pm 0.17 ; 6.474 \pm 1.578 ; 5.76 \pm 1.16$ and $23.154 \pm 4.744$ ) (Fig. 3).

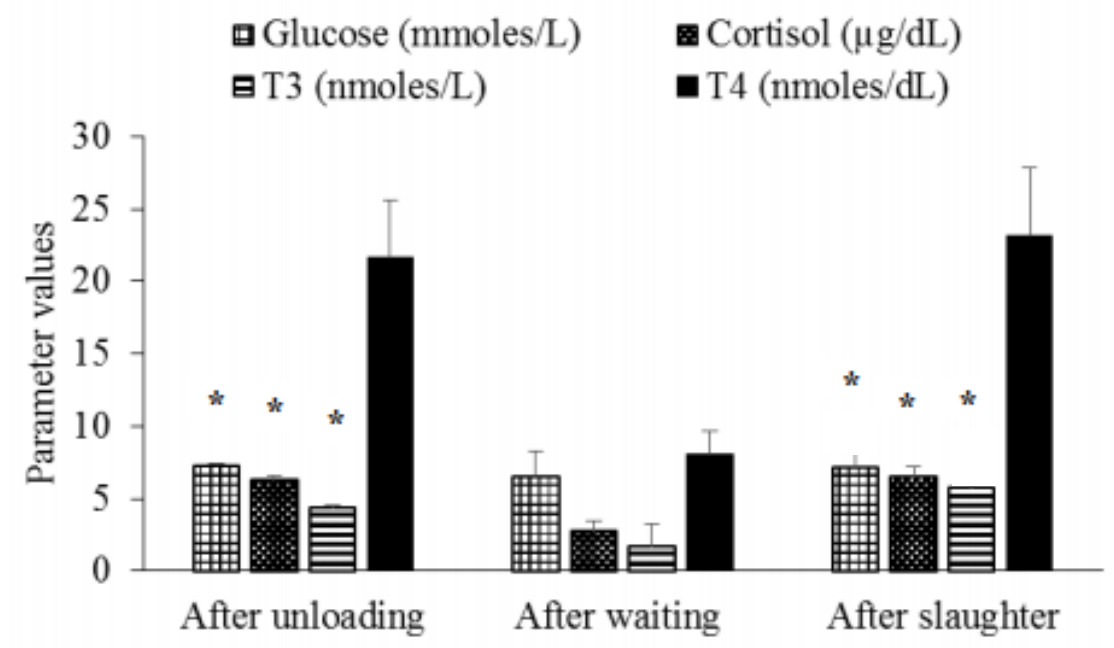

Fig. 3: Plasma levels of glucose, cortisol, triiodothyronine $\left(T_{3}\right)$ and thyroxine $\left(T_{4}\right)$ at 3 successive steps: after road transport ( $90 \mathrm{mn}$ ) and unloading (step 1), after a rest period of $20 \mathrm{~h}$ (step 2) and during bleeding after exposure to halal rite stress without stunning (step 3 ) in dromedary camels. $(\mathrm{M} \pm \mathrm{SEM}, * \mathrm{P}<0.05$ comparison with step 2) 
In the same conditions and camels, plasma levels of MDA (nM) measured after transport and unloading (3.56 \pm 0.24$)$ showed a significant decrease $(\mathrm{P}<0.05)$ after waiting $(1.46 \pm 0.34)$, then a significant increase after the stress induced by the slaughter procedure (5.28 \pm 0.47$)$. However, CATa (UI/dL) determined after transport and unloading $(4.05 \pm 0.23)$ showed a significant increase $(\mathrm{P}<0.05)$ after waiting $(6.20 \pm 0.32)$, then a significant decrease after the stress induced by the slaughter procedure (3.26 \pm 0.35$)$ (Fig. 4).

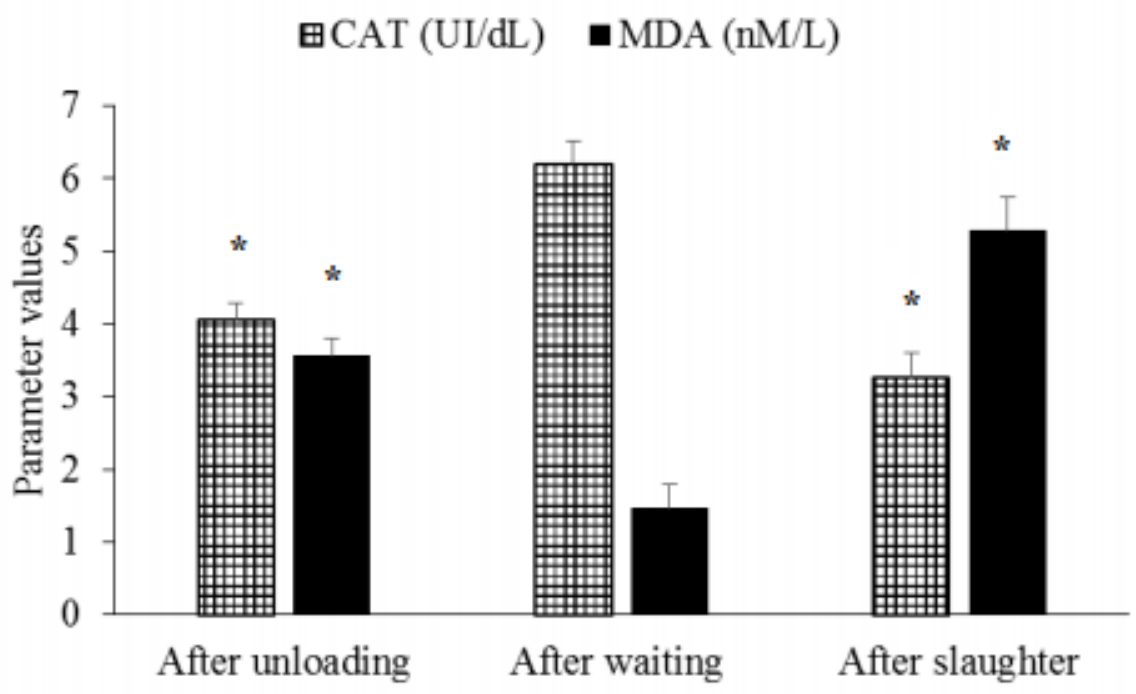

Fig. 4: Plasma levels of malondialdehyde (MDA) and catalase activity (CAT) at 3 successive steps: after road transport (90 $\mathrm{mn}$ ) and unloading (step 1), after a rest period of 20h (step 2) and during bleeding after exposure to halal rite stress without stunning (step 3 ) in dromedary camels. ( $\mathrm{M} \pm \mathrm{SEM}, * \mathrm{P}<0.05$ comparison with step 2)

\section{Discussion}

In this study, the responses to pre-slaughter stress in the dromedary camel, from the arrival at the slaughterhouse to bleeding according to the halal method, were evaluated during three steps: after transport and unloading (step 1), after waiting (step 2) and finally at bleeding (step 3), by analyzing several indicators of stress (NLR, H50, Hct, glucose, cortisol and thyroid hormones) and oxidant stress (MDA and CATa). The results showed that stress responses observed after transport and unloading were significantly attenuated after a rest period of 20 hours, but increased significantly again when the same camels were exposed to halal slaughter procedure. In fact, previous investigations had reported that the dromedary camel is very stressed by road transport (El Khasmi et al., 2013; El Khasmi et al., 2015), stocking density (Lemrhamed et al., 2018a) and a waiting duration less than 16 hours in the slaughterhouse (Lemrhamed et al., 2018b). The loading/unloading, environmental conditions during the transport, starvation/dehydration and lairage before slaughter are the most common stress factors for camels (El Khasmi et al., 2015; 
Lemrhamed et al., 2018a; Lemrhamed et al., 2018b), cows (Bourguet et al., 2010), pigs (Terlouw and Rybarczyk, 2008), lambs (Warriss, 2000) and goats (Gupta et al., 2019).

In domestic animals, the pre-slaughter stress steps start in the farm, breeding site and market, continue with loading, transport, unloading, reception, waiting in the slaughterhouse, and end at the killing (Terlouw et al., 2005; Melesse et al., 2011; Chen et al., 2013; Miranda-de la Lama, 2013). These steps should be taken into account, because it compromises their welfare and increase their vulnerability to diseases (Broom, 2014). So, the International Committee of the World Organization for Animal Health has developed recommendations in order to avoid their pre-slaughter and slaughter stress (Shimshony and Chaudry, 2005).

All values of stress and oxidant stress parameters analyzed here in the camel increased after road transportation and exposure to abattage procedure used in the abattoir. As a stressful factor, transport had been able to induce in the camel, hypercortisoleamia (Saeb et al., 2010; El Khasmi et al., 2013) and an activation of free radical generation (Nazifi et al., 2009). In the camel, hemolysis and circulating levels of cortisol, thyroid hormones and glucose after transport and unloading were significantly higher than those analyzed before transport, and were positively correlated with travel distance (El Khasmi et al., 2013; El Khasmi et al., 2015). In addition, road transport induced a significant increase of NLR and circulating levels of cortisol, glucose, lactate and heat shock protein 70 in bovine species (Grigor et al., 2004; Mounier et al., 2006; Chulayo et al., 2016). Leukocyte count using blood smears has been widely used as a reliable indicator for assessing stress in many domestic ruminants (Idrus et al., 2010; Wickham et al., 2012; Stockman et al., 2013) including the dromedary camel (Bargaâ et al., 2016). Thus, elevated NLR values were observed in cattle after transport step, and were positively correlated with blood levels of cortisol, glucose and lactate (Mounier et al., 2006; Davis et al., 2008). Several authors had reported a typical hemogram of adaptive responses in ruminants owing to stress, characterized by neutrophilia and lymphopenia (Ali et al., 2006; Minka et al., 2009; Miranda de la Lama et al., 2010).

Responses to halal slaughter stress evaluated by circulating levels of cortisol were correlated with duration of restraint, waiting time, duration of food deprivation (Bourguet et al., 2011) and age (Terlouw et al., 2011), and were influenced by sex (Welsh et al., 2009), race (Ndlovu et al., 2008) and water and food deprivation (Bourguet et al., 2011). The high blood levels of glucose and cortisol in stressed camels might be linked to higher reactivity to human and environmental factors involved in slaughter operations. In fact, both the sympathetic and the hypothalamic-pituitary-adrenal axis are involved when animals are exposed to stress, resulting in a release of cortisol and catecholamines which directly stimulate muscle and hepatic glycogen mobilization, leading to an increase of circulating glucose levels (Grandin, 1997; Kannan et al., 2000; Alcalde et al., 2011). 
The responses to slaughter stress could be influenced by unfamiliar environments such as abattoir design (Miranda-de la Lama et al., 2010), abattoir environment (Njisane and Muchenje, 2017), abattoir workers (Terlouw et al., 1998; Terlouw et al., 2011) and other animals from different farms and of other species (Vimiso et al., 2012). Moreover, Francesca Iulietto et al., (2018) stated that the loud noise at the abattoir might also affect the animals' response, as opposed to the quiet environment at the farm. Thus, in pigs, the reduction of ground surfaces (Marco-Ramell et al., 2011) reduce the resistance of animals to oxidative stress evaluated by measuring GPx activities or the appearance of peroxidation products. In farm animals, oxidative stress is caused by many stressful situations of physiological, environmental or nutritional origin, thus many biological molecules (lipids, proteins, carbohydrates, nucleic acids) can be "oxidized" by radical species generated (Durand et al., 2013). An animal's stress response is a complex interaction that depends on its past experiences, genetic factors, and non-aversive events such as normal circadian rhythms (Grandin, 1997). However, blood was taken from the dromedaries used in this study at three different times (after transport, after lairage ant at exsanguination), which could influence any results.

On the other hand, halal slaughter procedure may be another cause of stress that could be added to other physical, emotional, cognitive and social factors in the camel. This cause is very little described although it has a significant impact on the homeostasis of this species at slaughter. In fact, preslaughter factors such as social disturbances, exposure to novel or sudden events, visual, olfactory and audible context may be stressful (Bourguet et al., 2010; Bourguet et al., 2011), but the slaughter method could be a much more stressful factor. Thus, the levels of the stress indicators determined immediately at the exsanguination appeared much higher in animals slaughtered by the religious rite than in those ones traditionally slaughtered after stunning, in estearn Ethiopia camels (Seid et al., 2017) and calves (Fuseini et al., 2016). In the camel, slaughter method was likely very stressful and appeared to change markedly at the exsanguination in the levels of the stress indicators (cortisol, thyroid hormones, glucose, MDA, CATa, hemolysis and NLR). A possible reason for this was the fact that compared to other domestic animals, the slaughter procedure without stunning of camels is difficult for the operator and difficult for the animals because of their large size and aggressiveness, resulting in increased circulating levels of stress indicators. In fact, the camels were placed roughly in a squatting position, fixed in a caudal position and had direct visual contact with the operator responsible for halal bleeding. In addition, in the context of slaughter, the presence of humans, sudden events, sounds and rapid intermittent movement would be perceived by animals (Terlouw and Rybarczyk, 2008; Bourguet et al., 2010; Bourguet et al., 2011). Furthermore, the camels were slaughtered in front of other ones waiting for the slaughter, which could stress them at least in part, by volatile compounds in the urine, blood and feces (Terlouw et al., 1998; Terlouw et al., 2011). According to Kadim et al. (2013), the dromedary slaughter procedure requires experience from loading and transport to bleeding. Thus, the animal must be carefully unloaded as soon as it arrives at the slaughterhouse 
and drove calmly to the place of stabling to avoid any stress. The handling of the dromedary before slaughter has a significant effect on the quality characteristics of its meat. For example, rough handling before slaughter is responsible for the appearance of bruising at the bump of the carcass (Kadim et al., 2013). This species requires experience in all steps of preslaughter processes including the loading, transport, unloading, waiting and killing (Kadim et al., 2013). Finally, to reduce considerably the stress of halal slaughter method in the camel, several practical recommendations which may help to reduce considerably the stress of this species at slaughter may be proposed. The slaughtering must be instantaneously and may be performed only in such a manner as to avoid unjustified inflicting of pain, suffering, injury or fear on the animal. Not slaughtering an animal in front of others of its congeners, and not sharpening a knife in front of animals to be slaughtered. The bleeding trap used must be properly cleaned before introducing an animal to limit the presence of blood.

\section{Conclusion}

The dromedary camels were more susceptible to stress induced by transport and unloading reflected by significant high circulating levels of cortisol, thyroid hormones, MDA and glucose, hemolysis and NLR, and low CAT activity. All these stress responses were significantly reduced after the waiting period, but increased again after exposure to the halal slaughter procedure used in the slaughterhouses in Morocco. This procedure could be considered the final step most stressful like that of unloading consecutive to transport. This animal could not escape the impact of this slaughtering stress, even if the rest period is largely sufficient. Thus, to alleviate these stressful assaults incurred to dromedary camels due to transport and pre-slaughter stress, it appears very useful to provide adequate camel-rest time with access to water, encourage the distribution of energy supply before transport and promote a positive attitude towards camel sensitivity during slaughter. As future aspect of this research work, the impact of halal slaughter procedure stress on meat quality will be evaluated in the camel.

\section{Acknowledgments}

The authors thank the President of urban municipalities of Casablanca and Dr. Abouhafs Rachid the responsible for prefectural veterinary service of Casablanca, to carry out this work.

\section{References}

1. Alcalde, M.J., Alvarez, R., Pérez-Almero, J.L., Cruz, V. and Rodero, E. (2011). Effect of time road transport on some blood indicators of welfare in suckling kids. In Proceeding of the 62nd Annual Meeting of the European Association for Animal Production (EAAP). Wageningen Academic Publishers, Wageningen, The Netherlands, pp. 252.

2. Ali, B.H., Al-Qarawi, A.A. and Mousa, H.M. (2006). Stress associated with road transportation in desert sheep and goats, and the effect of pretreatment with xylazine or sodium betaine. Research in Veterinary Science, 80: 343-348. 
3. Bargaa, R., Lektib, I., Barka, K., El Abbadi, N., Belhouari, A., Hammoumi, A., and El Khasmi, M. (2016). Seasonal Variations of Heamatological Profile and its Correlations with Thyroid and Adrenal Gland Hormones in Male Moroccan Camel (Camelus dromedarius). International Journal of Agricultural and Environmental Sciences, 1(1): 8-14.

4. Bourguet, C., Deiss, V., Gobert, M., Durand, D., Boissy, A., and Terlouw E.M.C. (2010). Characterising the emotional reactivity of cows to understand and predict their stress reactions to the slaughter procedure. Applied Animal Behaviour Science, 125: 9-21.

5. Bourguet, C., Deiss, V., Tannugi, C. C., and Terlouw, E. M. C. (2011). Behavioural and physiological reactions of cattle in a commercial abattoir: Relationships with organisational aspects of the abattoir and animal characteristics. Meat Science, 88(1): 158-168.

6. Broom, D.M. (2014). Welfare of transported animals: Factors influencing welfare and welfare assessment. In Livestock Handling and Transport. 4th ed. Edited by T. Grandin. CABI, Wallingford, Oxfordshire. p. 23-38.

7. Chen, X.Y., Jiang, R.S, and Geng, Z.Y. (2013). Differential effects of two indigenous broilers exposed to cold stress and characters of follicle density and diameter. Ital. J. Anim. Sci, 10: 38-41.

8. Chulayo, A.Y., Bradley, G., and Muchenje, V. (2016). Effects of transport distance, lairage time and stunning efficiency on cortisol, glucose, HSPA1A and how they relate with meat quality in cattle. Meat Sci. 117: 89-96.

9. Durand, D., Damon, M, and Gobert, M. (2013). Oxidative stress in farm animals: General aspects. Cahiers de nutrition et de diététique, 48: 218-224. (in french)

10. El Khasmi, M., Chakir, Y., Bargaâ, R., Barka, K., Lektib, I., El Abbadi, N., Belhouari, A., and Faye, B. (2015). Impact of transport distance on stress biomarkers levels in dromedary camel (Camelus dromedarius). Emirates Journal of Food and Agriculture, 27(6): 507-512.

11. El Khasmi, M., Chakir, Y., Riad, F., Safwate, A., Tahri, El., Farh, M., El Abbadi, N., Abouhafs, R., and Faye, B. (2013). Effects of Transportation Stress during the Hot-Dry Season on Some Haematological and Physiological Parameters in Moroccan Dromedary Camels (Camelus dromedarius). Journal of Life Sciences (USA), 7(1): 13-25.

12. Francesca Iulietto, M., Sechi, P., Mansi Gaudenzi, C., Grispoldi, L., Ceccarelli, M., Barbera, S. and Terzo Cenci-Goga, B. (2018). Noise assessment in slaughterhouses by means of a smartphone app. Italian Journal of Food Safety, 7: 7053.

13. Fraukner, W.R., and King, J.W. (1970). Manual of Clinical Laboratory Procedures. Clevel, Ohio. p. 354.

14. Fuseini, A., Knowles, T.G., Lines, J.A., Hadley, P.J., and Wotton, S.B. (2016). The stunning and slaughter of cattle within the EU: A review of the current situation with regard to the halal market. Animal Welfare, 25: 365-376.

15. Grandin, T. (1997). Assessment of stress during handling and transport. J Anim Sci, 75: 249-257.

16. Grigor, P. N., Cockram, M.S., Steele, W.B., McIntyre, J., Williams, C.L., Leushuis, I.E. and van Reenen, C.G. (2004). A comparison of the welfare and meat quality of veal calves slaughtered on the farm with those subjected to transportation and lairage. Livest. Produc. Sci, 91: 219-228.

17. Gupta, D., Ashutosh, M., Kashyap, G., Punetha, M., Patel, B., Ashutosh, Para, I., Tejaswi, V., Jalmeria, N. and Ahirwar, M. (2019). Physiological response to transportation stress at different flocking densities in hot humid and winter seasons in goats and assessment of pretreatment of Vitamin C, Electrolyte and Jaggery. Indian J. Anim. Res, 53: 299-306.

18. Idrus, Z., Bahyuddin, N., Wai, C.Y., Farjam, A.S., Sazili, A.Q., Rajion, M.A. and Meng, G.Y. (2010). Physiological responses in goats subjected to road transportation under the hot, humid tropical conditions. Int. J. Agric. Biol, 12: 840-844.

19. Kadim, I.T., Mustafa, M.F., Mahgoub, O., and Bekhit, A. (editors) (2013). Slaughtering and Processing of Camels. In: Camel meat and meat products / CAB International, p54-72. 
20. Kannan, G., Terrill, T.H., Kouakou, B., Gazal, O.S., Gelaye, S., Amoah, E.A. and Samake S. (2000). Transportation of goats: effects on physiological stress responses and live weight loss. Journal of Animal Science, 78: 1450-1457.

21. Lemrhamed, A., Farh, M., Riad, F., El Abbadi, N., Tahri, E., Belhouari, A., Faye, B. and El Khasmi M. (2018). Evaluation of stress responses induced by the loading density in dromedary camel (Camelus dromedarius). Emir. J. Food Agric, 30(9): 803-808.

22. Lemrhamed, A., Farh, M., Riad, F., El Abbadi, N., Tahri, E., Faye, B. and El Khasmi, M. (2018). Impact of lairage time at slaughterhouse on physiological biomarkers of stress in dromedary camel (Camelus dromedarius). Proceedings the $5^{\text {th }}$ Conference of the International Society of Camelid Research and development ISOCARD. Laâyoune, Morocco, November 12-15, P 323-324.

23. Marco-Ramell, A., Pato, R., Pẽna, R., Saco, Y., Manteca, X., Ruiz de la Torre, J.L. et al. (2011). Identification of serum stress biomarkers in pigs housed at different stocking densities, Vet J. 190(2): e66-71.

24. Melesse, A., Maak, S., Schmidt, R. and Von Lengerken, G. (2011). Effect of long-term heat stress on enzyme activities and T3 levels in commercial layer hens. Int. J. Livest. Prod, 2 (7): 107-116.

25. Ministry of Agriculture. (2018). The camel sector as part of the Moroccan green plan. The 5th ISOCARD Meeting, 12-15 November, Laâyoune, Morocco.

26. Minka, N.S, Ayo, J.O, Sackey, A.K.B and Adelaiye, A.B. (2009). Assessment and scoring of stresses imposed on goats during handling, loading, road transportation and unloading, and the effect of pretreatment with ascorbic acid. Livestock Science, 125: 275-282.

27. Miranda de la Lama, G.C, Villarroel, M., Liste, G., Escós, J. and María, G.A. (2010). Critical points in the pre-slaughter logistic chain of lambs in Spain that may comprise the animal's welfare. Small Ruminant Research, $90: 174-178$.

28. Miranda-de la Lama, G.C., Pascual-Alonso, M., Guerrero, A., Alberti, P., Alierta, S., Sans, P., Gajan, JP., Villarroel, M., Dalmau, A., Velarde, A., Campo, M.M, Galindo, F., Santolaria, M.P., Sañudo, C., and María, G.A. (2013). Influence of social dominance on production, welfare and the quality of meat from beef bulls. Meat Sci, 94 (4): 432-437.

29. Mounier, L., Dubroeucq, H., Andanson, S. and Veissier, I. (2006). Variations in meat pH of beef bulls in relation to conditions of transfer to slaughter and previous history of the animals. Journal of Animal Science, 84: 1567-1576.

30. Nazifi, S., Mahdi, S., Hasan, B. and Saeedeh, S. (2009). Influence of road transportation during hot summer conditions on oxidative status biomarkers in Iranian dromedary camels (Camelus dromedarius). Afr. J. Biochem. Res. 3: 282-287.

31. Ndlovu, T., Chimonyo, M., Okoh, A.I, and Muchenje V. (2008). A comparison of stress hormone concentrations at slaughter in nguni, bonsmara and angus steers. African Journal of Agricultural Research. 3: 96-100.

32. Ndou, S.P., Muchenje, V., and Chimonyo, M. (2011). Assessment and implications of animal welafere in beef production systems in developing countries. Afr J Biotechnol, 10: 1049-64.

33. Njisane, Y.Z, and Muchenje V. (2017). Farm to abattoir conditions, animal factors and their subsequent effects on cattle behavioural responses and beef quality. A review. Asian-Australas $J$ Anim Sci, 30:755-764.

34. O'Dell, B.L., Browning, J.D. and Reeves, P.G. (1987). Zinc deficiency increases the osmotic fragility of rat erythrocytes. J. Nutr. 117: 1883-1889.

35. Saeb, M., Baghshani, H., Nazifi, S. and Saeb, S. (2010). Physiological response of dromedary camels to road transportation in relation to circulating levels of cortisol, thyroid hormones and some serum biochemical parameters. Trop. Anim. Health and Prod. 42: 55-63.

36. Seid, A., Kurtu, M.Y. and Urge, M. (2017). Slaughter practices and composition of dromedary camel (Camelus dromedarius) meat in relation to age and body condition in Eastern Ethiopia. Journal of Agriculture and Environment for International Development - JAEID. 111 (1): 191-206.

37. Shimshony, A., and Chaudry, M.M., (2005). Slaughter of animals for human consumption. Rev. Sci. 
Tech. 24(2): 693-710.

38. Stockman, C.A., Collins, T., Barnes, A.L., Miller, D., Wickham, S.L., Beatty, D.T., and Fleming, P.A. (2013). Flooring and driving conditions during road transport influence the behavioural expression of cattle. Applied Animal Behaviour Science. 143(1): 18-30.

39. Terlouw, C., Bourguet, C., Cohen Tannugi, C. and Deiss, V. (2011). Stress Reactions of Cattle in a French Industrial Slaughterhouse. Viandes \& Produits Carnés - 28 September.

40. Terlouw, C. (2005). Stress reactions at slaughter and meat quality in pigs: genetic background and prior experience: A brief review of recent findings. Livest Prod Sci. 94: 125-135.

41. Terlouw, E.M.C., and Rybarczyk, P. (2008). Explaining and predicting differences in meat quality through stress reactions at slaughter: The case of Large White and Duroc pigs. Meat Science. 79: 795805.

42. Terlouw, E.M.C, Boissy, A., and Blinet, P. (1998). Behavioural responses of cattle to the odours of blood and urine from conspecifics and to the odour of faeces from carnivores. Appl. Anim. Behav. Sci. 57: 9-21.

43. Vimiso, P., Muchenje, V., Marume, U. and Chiruka, R. (2012). Preliminary study on consumers' and meat traders' perceptions of beef quality and how the beef quality is affected by animal welfare practices. Sci Res Essays. 7: 2037-2048.

44. Warriss, P.D. (2000). Meat Science: An Introductory Text. New York, NY: CABI Publishing.

45. Welsh, J.T. et al. (2009). Influence of gender and breed type on basal and induced secretion of cortisol in cattle. Conference at the 91st Annual Meeting of the Endocrine Society, Washington, D.C., P2-640.

46. Wickham, S.L., Collins, T., Barnes, A.L., Miller, D., Beatty, D.T., Stockman, C., Blache, D., Wemelsfelder, F., and Fleming, P.A. (2012). Qualitative behavioural assessment of transport-naïve and transport habituated sheep. J. Anim. Sci, 90 (12): 4523-4535. 